\title{
DESARROLLO DE HUEVOS Y LARVAS TEMPRANAS DE LA MERLUZA DEL SUR, MERLUCCIUS AUSTRALIS, CULTIVADOS BAJO CONDICIONES DE LABORATORIO
}

\author{
DEVELOPMENT OF EGGS AND EARLY LARVAE OF THE SOUTHERN \\ HAKE MERLUCCIUS AUSTRALIS, REARED UNDER \\ LABORATORY CONDITIONS
}

\author{
Claudia A. Bustos ${ }^{1} \&$ Mauricio F. Landaeta ${ }^{2}$ \\ ${ }^{1}$ Programa Magíster en Ciencias mención Zoología, Universidad de Concepción, Email: cbustos@udec.cl, \\ Casilla 160-C, Correo 3, Concepción, Chile \\ ${ }^{2}$ Programa Doctorado en Oceanografía, Universidad de Concepción
}

\section{RESUMEN}

Se describe por primera vez el desarrollo embrionario y larval temprano de la merluza del sur, Merluccius australis, utilizando ejemplares cultivados en el laboratorio. Los huevos miden 0,9-1,1 mm de diámetro, tienen corion liso, vitelo no segmentado y presentan 1 gota oleosa de 0,19-0,27 mm de diámetro. Las larvas mantenidas a $11,5^{\circ} \mathrm{C}$ eclosionan 7 días después de la fertilización con un tamaño promedio $2,8 \mathrm{~mm} \mathrm{LN}$ (longitud notocordal); el vitelo se absorbe completamente en 9 días. Las larvas con saco vitelino crecen a una tasa lineal de $0,15 \mathrm{~mm} /$ día. El crecimiento se reduce significativamente (test de pendientes múltiples, p <0,001) a $0,08 \mathrm{~mm} /$ día, desde la primera alimentación hasta los 45 días de vida.

Palabras Claves: Merluccius australis, huevos, larvas con saco vitelino, crecimiento, cultivo.

\section{ABSTRACT}

The embryonic and early larval development of the southern hake, Merluccius australis, is described for the first time using laboratory reared specimens. The eggs are pelagic, measure 0.9-1.1 mm diameter, have smooth chorion, unsegmented yolk and one $0.19-0.27 \mathrm{~mm}$ diameter oil globule. At a temperature of $11.5^{\circ} \mathrm{C}$ the larvae hatch 7 days after fertilization, at an average size of $2.8 \mathrm{~mm}$ NL (notochord length); yolk reserves are exhausted in 9 days. Yolk-sac larvae grow at a linear rate of $0.15 \mathrm{~mm} /$ day. Growth rate is reduced to $0.08 \mathrm{~mm}$ /day from first feeding to 45 days (multiple slope test, $\mathrm{p}<0.001$ ).

KeYwords: Merluccius australis, eggs, yolk-sac larvae, growth, culture

\section{INTRODUCCION}

La merluza del sur, Merluccius australis Hütton 1872, es un pez de hábitos demersales del Pacífico suroriental que se distribuye en Chile por el norte desde la VIII Región (38²2'S) hasta los $55^{\circ} \mathrm{S}$. Batimétricamente, la especie se distribuye entre los 70-100 $\mathrm{m}$ de profundidad en las aguas interiores de los canales y fiordos de la X y XI regiones, hasta profundidades entre 200 y $500 \mathrm{~m}$ en las 
aguas exteriores de la zona austral (Lillo et al. 1997). Según Balbontín \& Bravo (1993) esta especie presenta un ciclo de madurez gonádica que se inicia entre los meses de febrero y abril, y concluye con desoves masivos en los meses de julio, agosto y septiembre. Rubilar et al. (2002) definen el área entre isla Guafo e isla Guamblin, XI Región, como zona de desove de la especie.

Esta especie ha sido objeto de una pesquería industrial desde 1978 y alcanzó su mayor desembarque histórico en 1988, con 70 mil toneladas aproximadamente. Sin embargo, a partir de esa fecha comenzó una disminución paulatina de las capturas, las que llegaron a 23.431 toneladas en 2002 (Sernapesca 2003). Las disminuciones de las capturas y la alta demanda de esta especie, particularmente por el mercado español, que es el destino del $93 \%$ de la captura en los últimos 5 años (Güelfo 2004), han generado un interés por su cultivo a nivel industrial, desde la obtención de gametos, el cultivo de huevos y larvas, hasta la producción de juveniles.

Fundación Chile, a través del proyecto FONDEF D00I1084 "Desarrollo de cultivos de peces de aguas marinas", ha logrado exitosamente la reproducción de adultos en cautiverio, y el crecimiento de larvas y juveniles. El objetivo del presente trabajo es describir por primera vez el desarrollo embrionario de la merluza del sur y caracterizar su crecimiento larval temprano bajo condiciones de laboratorio.

\section{MATERIALES Y METODOS}

Desde el año 2000 se mantuvo un cultivo de adultos de merluza austral, obtenidos de capturas con espineles, bajo condiciones naturales de luz en el Centro Experimental Quillaipe de la Fundación Chile, Puerto Montt, Chile. En septiembre de 2002 los peces sexualmente maduros fueron inducidos al desove con hormona gonadotrópica coriónica humana (GnRH, Ovaplant ${ }^{\circledR}$, Syndel Laboratorios Inc., Canadá), administrada mediante inyecciones intramusculares en la región dorsal. Los peces tratados fueron ubicados en estanques con aireación y flujo de agua continuo, hasta que las hembras alcanzaron la hidratación de sus ovocitos.

Posteriormente, se recolectaron óvulos y espermatozoides de una hembra y un macho, los que fueron combinados en agua de mar filtrada a temperatura ambiente $\left(11^{\circ} \mathrm{C}\right)$. Después de la fertilización, se separaron los óvulos fecundados de los no fecundados. Los cigotos viables (i.e., con boyantez positiva) se trasladaron a un estanque cilindro-cónico de 3001 de capacidad, con agua de mar filtrada

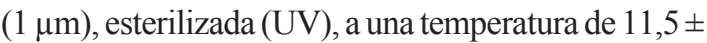
$1^{\circ} \mathrm{C}$. Para determinar el estado de desarrollo de los huevos, cada 15 minutos se recolectaron muestras de 10-30 ejemplares, los que fueron preservados en etanol al 90\%, formalina al 5\% y glutaraldehído. Adicionalmente se registraron in vivo los diferentes estados embrionarios, utilizando un microscopio con equipo fotográfico incorporado, a excepción de las larvas que fueron fotografiadas una vez preservadas en etanol. Posterior a la absorción del vitelo, las larvas fueron alimentadas con microalgas Isocrysis galbana, rotíferos y nauplius de Artemia salina.

Una vez ocurrida la eclosión, cada día y hasta los 45 días de vida se seleccionaron aleatoriamente entre 3 y 10 larvas que fueron anestesiadas con MS 222 y posteriormente preservadas en etanol al 90\%. Para las mediciones de huevos y larvas se utilizó una cámara de video montada a un estereo-microscopio Olympus, utilizando el software OPTIMAS ${ }^{\circledR}$ (versión 6.1). El volumen del vitelo $\left(\mathrm{mm}^{3}\right)$ se estimó según la ecuación de un esferoide, $4 / 3 \pi\left(\mathrm{a}^{*} \mathrm{~b}^{2}\right)$, donde a es la mitad de la longitud máxima del vitelo, y $b$ es la mitad del ancho máximo del saco vitelino.

Para determinar la tasa de crecimiento durante el periodo de alimentación endógena, posterior a la utilización del vitelo y para todo el periodo larval, se calcularon regresiones lineales por ajuste de mínimos cuadrados, con un intercepto fijo de 2,79 (tamaño de eclosión obtenido experimentalmente). La absorción del saco vitelino fue obtenida ajustando un modelo exponencial negativo.

\section{RESULTADOS}

Los huevos obtenidos de merluza del sur son esféricos, de diámetro entre 0,90 y $1,12 \mathrm{~mm}$. Presentan un corion sin ornamentaciones, espacio perivitelino pequeño y vitelo sin granulaciones. El huevo posee una gota oleosa de color anaranjado de 0,19 - 0,27 $\mathrm{mm}$ de diámetro.

Cuando el huevo es fecundado el cigoto unicelular se divide en dos células a las 4 horas (Fig. 1a, Tabla I); una hora después aparecen 4 blastómeros (Fig. 1b). El citoplasma tiende a ser más pálido que el vitelo y puede contener pequeños gránulos. El proceso de 
segmentación continúa y a las 7 horas postfecundación (PF) se divide en 8 blastómeros (Fig. 1c). Luego de 8 horas PF se hacen aparentes 16 blastómeros (Fig. 1d). La mórula temprana se origina a las 14 horas PF; en este punto los blastómeros individuales ya no son distinguibles y comienza la evaginación para la formación del embrión (Fig. 1e). La gastrulación va ocurriendo a medida que el periblasto va desplazándose por epibolía (desplazamiento del blastodermo alrededor del vitelo); este proceso se evidencia por el engrosamiento del escudo embrional. El escudo embrional es una masa de células en forma de campana que prolifera hacia dentro desde el margen del blastodisco, formando el eje del embrión. Adicionalmente, se hace evidente una pigmentación puntiforme y uniforme sobre el vitelo (Fig. 1f). Luego el eje embrional se extiende hacia el borde del anillo germinal. Posteriormente se hacen aparentes el cerebro, las vesículas ópticas y los somitos o miómeros del tronco del embrión. A las 145 horas post-fecundación comienzan a desarrollarse grandes melanóforos dendríticos sobre la zona dorsal del embrión, particularmente sobre la cabeza y tronco (Fig. 1g); la gota oleosa también presenta pequeños pigmentos puntiformes no distinguibles en las fotografías. A las $160 \mathrm{~h}$ los primordios de los lentes se comienzan a formar en los ojos y la punta de la cola empieza a engrosarse levemente. Previo a la eclosión, la cola se separa de la masa vitelina y se hacen evidentes los primordios de la aleta pectoral. La eclosión ocurre aproximadamente a las 175 horas PF aproximadamente (7 días, Fig. 1h) a $11,5^{\circ} \mathrm{C}$.

Se observó un bajo porcentaje de malformaciones tanto en huevos como larvas recién eclosionadas $(<15 \%)$. En el caso de los huevos se denotó embriones con la región cefálica o la cola formando un ángulo de $90^{\circ}$ con el resto del cuerpo (Fig. 1g, huevo de la izquierda), y embriones con la cabeza de tamaño inferior a la normal. En cuanto a las larvas, algunos ejemplares no presentaron pigmentación en los ojos y no apertura de la boca y algunos no formaron el ano.

Las larvas recién eclosionadas miden 2,79 $\pm 0,14 \mathrm{~mm}$ LN (promedio \pm 1 desviación estándar), poseen un saco vitelino de 1,5-2,3 $\mathrm{mm}^{3}$ en volumen. En las condiciones de temperatura utilizadas, $11,5^{\circ} \mathrm{C}$, el vitelo se utiliza completamente en 9 días, período durante el cual las larvas crecen a una velocidad de $0,153 \mathrm{~mm} /$ día (Fig. 2a, Tabla II). El vitelo se agota exponencialmente de acuerdo a la ecuación $y=1.698$ e $-0.32 x$,

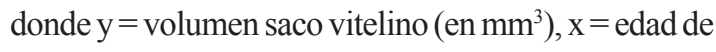
la larva (en días) (Fig. 2b). Al finalizar el periodo de alimentación endógena las larvas presentan un tamaño de 4,7 a 5,1 mm LN; los ojos que comenzaron a pigmentarse al día 4 ya están completamente desarrollados y la boca es funcional (Tabla I).

Durante el desarrollo temprano las larvas presentan melanóforos estrellados en la zona frontal de la cabeza, una serie de melanóforos dendríticos inmediatamente detrás de las cápsulas óticas, sobre el tronco, y otra serie de igual forma detrás del saco vitelino. Adicionalmente, se observa un melanóforo en la cara interna de la aleta pectoral. En la región de la cola se reconoce un melanóforo dendrítico extendido en la parte media inferior, en el segundo tercio posterior y en la región caudal en posición hipural, con melanóforos sobre y bajo el extremo del notocordo (Fig. 1h). Sobre el saco vitelino se distinguen dos prominentes melanóforos estrellados en parte anterior superior, uno a cada lado, e inmediatamente bajo los ojos. Esta pigmentación característica se mantiene en larvas en pre y postflexión (Ciechomsky \& Weiss 1974; Balbontín et al. 2004).

En el período de alimentación exógena, las larvas reducen su tasa de crecimiento diario a $0,083 \mathrm{~mm} /$ día (Tabla II) hasta los 45 días de vida. Esta tasa de crecimiento es significativamente menor al crecimiento diario observado durante la etapa de alimentación a través del saco vitelino (test de pendientes múltiples ANCOVA, $\mathrm{t}=11,001, \mathrm{v}=194, \mathrm{p}<0,001)$.

\section{DISCUSION Y CONCLUSIONES}

En general, los huevos de los peces de la familia Merluccidae son muy similares (Fischer 1959, Fahay 1983, Moser et al. 1997) y coinciden con las medidas morfométricas de los huevos de merluza del sur obtenidas en este trabajo. La descripción tentativa realizada por Pool et al. (1997) a partir de huevos recolectados en la zona interior de los canales australes de la XI Región concuerda con la obtenida en este estudio. Aunque en esta zona también se ha detectado la presencia de merluza común, Merluccius gayi, cuyos huevos presentan características generales similares (Fischer 1959, Santander \& de Castillo 1969), el diámetro de los huevos y la gota oleosa de esta última especie son levemente mayores (huevo de hasta 1,23 mm de diámetro, gota oleosa entre 0,21 y $0,30 \mathrm{~mm}$ de diámetro). 
Desarrollo de M. australis cultivadas en laboratorio. Bustos, C. ET AL.

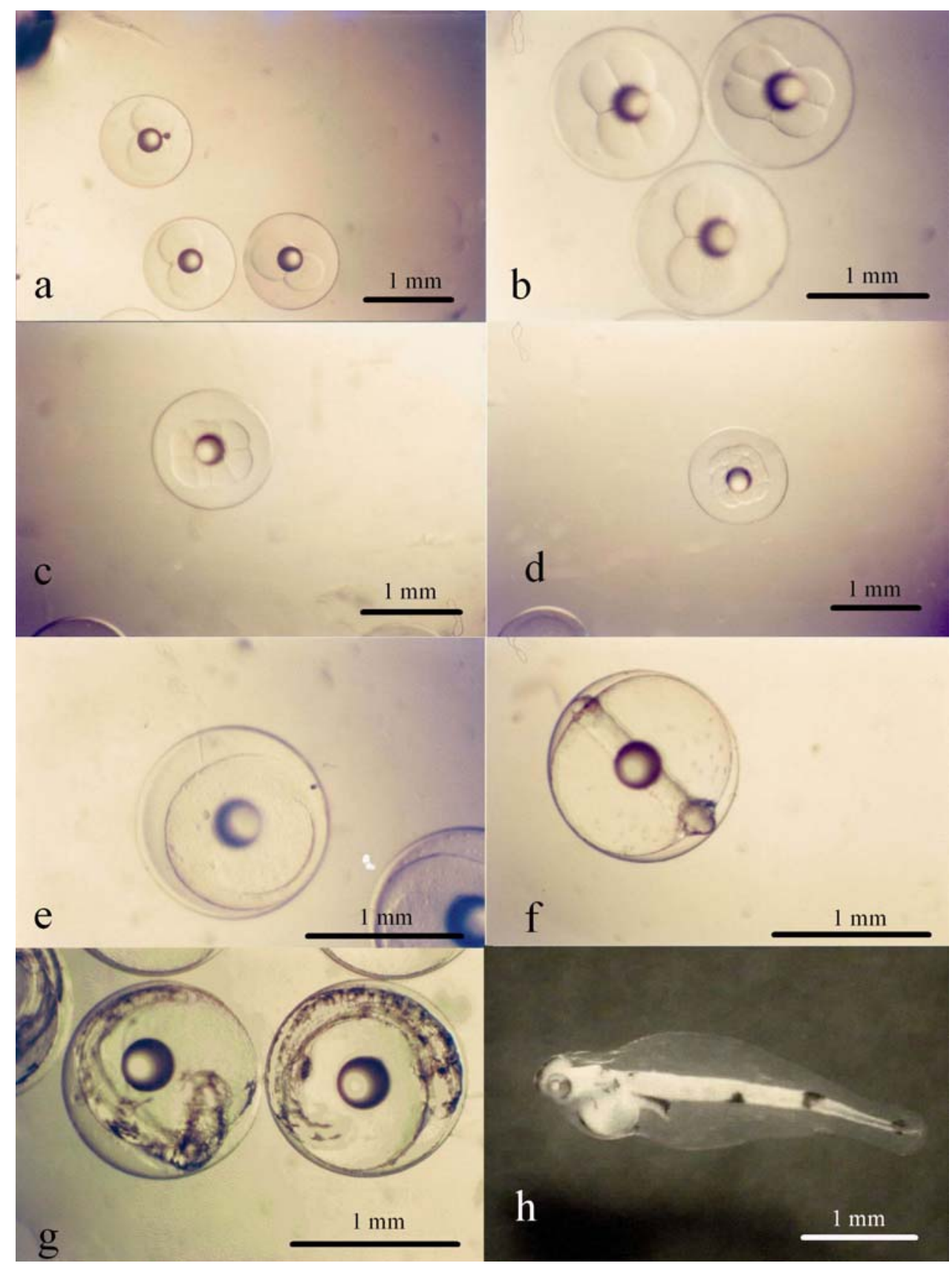

Figura 1. Desarrollo embrionario y larval temprano de Merluccius australis. a) 2 células, b) 4 células, c) 8 células, d) 16 células, e) estado de epibolía, f) huevo con embrión en desarrollo, g) huevo con embrión avanzado y h) larva con saco vitelino.

FIGURE 1. Embryos and yolk sac larvae development of Merluccius australis, a) 2 cells, b) 4 cells, c) 8 cells, d) 16 cells, e) stage of epiboly, f) egg with developmental embryo, g) egg with late embryo, and h) yolk-sac larva. 
Gayana 69(2), 2005

TABLA I. Desarrollo embrionario y larval de la merluza del sur, Merluccius australis a $11,5 \pm 1{ }^{\circ} \mathrm{C}$.

TABLE I. Embryonic and larval development of the southern hake, Merluccius australis at 11,5 $\pm 1^{\circ} \mathrm{C}$.

\begin{tabular}{cl}
\hline h: min & Etapas de desarrollo desde la fecundación \\
\hline $0: 00$ & Fecundación \\
$4: 00$ & Primera división \\
$5: 00$ & Segunda división \\
$7: 00$ & Tercera división \\
$8: 00$ & Cuarta división \\
$14: 00$ & Mórula temprana \\
$23: 30$ & Mórula tardía \\
$48: 00$ & Blástula \\
$60: 00$ & Gástrula \\
$145: 00$ & Cromatóforos sobre parte anterior del embrión \\
$175: 00$ & Inicio de la eclosión \\
\hline días & Etapas de desarrollo después de la eclosión \\
\hline 4 & Comienzo de pigmentación de los ojos \\
7 & Ojos completamente pigmentados \\
8 & Boca funcional \\
9 & Agotamiento del saco vitelino \\
\hline
\end{tabular}

TABLA II. Crecimiento larval de merluza del sur, Merluccius australis, a $11,5 \pm 1^{\circ} \mathrm{C}$, utilizando un modelo lineal por mínimos cuadrados. $\mathrm{LN}=$ Longitud notocordal.

TABLE II. Larval growth of southern hake, Merluccius australis at $11,5 \pm 1^{\circ} \mathrm{C}$, using a linear model by least squares. $\mathrm{LN}$ $=$ Notochordal length.

\begin{tabular}{ll}
\hline & Modelo lineal \\
\hline $\begin{array}{l}\text { Etapa de saco vitelino } \\
0 \text { a } 9 \text { días }\end{array}$ & Edad $=3,25 \mathrm{~mm} \mathrm{LN}+0,15 \mathrm{~mm} /$ día \\
$\begin{array}{l}\text { Etapa de alimentación exógena } \\
10 \text { a } 45 \text { días }\end{array}$ & $\mathrm{Edad}=3,32 \mathrm{~mm} \mathrm{LN}+0,08 \mathrm{~mm} /$ día \\
$\begin{array}{l}\text { Período total } \\
\text { 0 a } 45 \text { días }\end{array}$ & $\mathrm{Edad}=3,40 \mathrm{~mm} \mathrm{LN}+0,08 \mathrm{~mm} /$ día \\
\hline
\end{tabular}



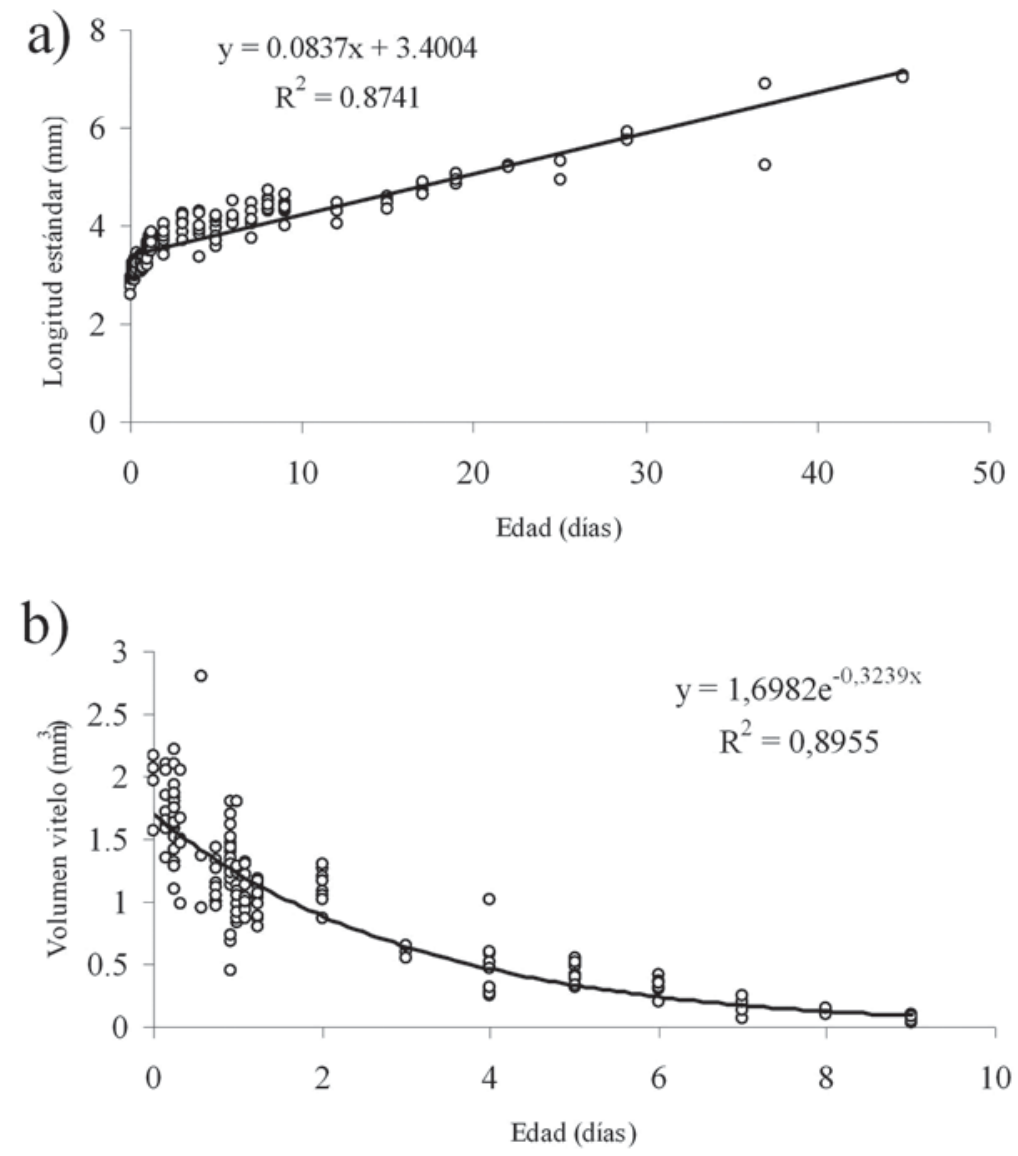

Figura 2. a) Tasa de crecimiento larval de Merluccius australis a $11.5^{\circ} \mathrm{C}$. b) Tasa de absorción del vitelo de larvas en alimentación endógena cultivada a $11.5^{\circ} \mathrm{C}$.

Figure 2. a) Larval growth rate of Merluccius australis at $11.5^{\circ} \mathrm{C}$. b) Yolk-sac absorption rate of endogenous feeding larvae cultured at $11.5^{\circ} \mathrm{C}$.

El tiempo de desarrollo del estado de huevo obtenido a $11,5^{\circ} \mathrm{C}$ ( 7 días ) fue similar al descrito por Bailey (1982) para huevos de Merluccius productus $(6,4$ días a $\left.12^{\circ} \mathrm{C}\right)$, y mayor al de los huevos de merluza común, Merluccius gayi cultivados a $12,8-14,5^{\circ} \mathrm{C}$ (4 días, Fischer 1959). Estas diferencias en tiempo de desarrollo embrionario pueden ser atribuibles al efecto de la temperatura más que al tamaño de los huevos (Pepin et al. 1997).

Las larvas recién eclosionadas de Merluccius gayi también son relativamente de mayor tamaño que las de merluza del sur (entre 3,05 y 3,35 vs 2,79 mm LN) y presentan una pigmentación levemente diferente (Fischer 1959). Ambas especies comparten los mis- mos patrones pigmentarios (melanóforos estrellados sobre la región de la cabeza, sobre el tronco, en el vitelo, y un gran melanóforo dendrítico ventral en el primer tercio de la región de la cola); sin embargo, en la merluza común se observan dos grupos de pigmentos estrellados ubicados en la zona dorsal y ventral del segundo tercio de la cola (sobre los miómeros postanales 20-25, Fischer 1959). En cambio, en larvas de Merluccius australis obtenidas en laboratorio (este estudio) y en terreno (Ciechomsky \& Weiss 1974; Balbontín et al. 2004) no está presente el grupo ventral de melanóforos; adicionalmente, la pigmentación en el extremo caudal en larvas de merluza del sur no se observa en merluza común. 


\section{AGRADECIMIENTOS}

Los autores quieren agradecer al Sr. Rodrigo Lewis y al proyecto FONDEF D00I1084 "Desarrollo de cultivos de peces de aguas marinas", por las facilidades para llevar a cabo el presente trabajo. Agradecemos al Dr. Guillermo Herrera por sus aportes en una versión temprana del manuscrito, y a dos revisores anónimos que mejoraron la versión final. Durante el desarrollo del presente trabajo la autora principal fue financiada por una beca de exención de matrícula de la Escuela de Graduados de la Universidad de Concepción y el segundo autor fue financiado por una beca doctoral CONICYT.

\section{BIBLIOGRAFIA}

Bailey, K. M. 1982. The early life history of the Pacific hake, Merluccius productus. Fish. Bull. 80(3): 589-598.

Balbontín, F. \& R. Bravo. 1993. Fecundidad, talla de la primera madurez sexual y datos biométricos en la merluza del sur Merluccius australis. Rev. Biol. Mar. 28(1): 111-132.

Balbontín, F., F. Uribe, R. Bernal \& M. Braun. 2004. Descriptions of larvae of Merluccius australis, Macruronus magellanicus, and observations on a larva of Micromesistius australis from southern Chile (Pisces: Gadiformes). New Zealand J. Mar. Fresh. Res. 38: 609-619.

Ciechomski, J. D. \& G. Weiss. 1974. Características del desarrollo embrionario y larval de las merluzas Merluccius merluccius hubbsi y Merluccius polylepis (Pisces: Merlucciidae). Phycis 33(87): 527-536.
FAHAY, M. P. 1983. Guide to the early stages of marine fishes occurring in the western North Atlantic Ocean, Cape Hateras to the southern Scotian Shelf. J. Northwest Atl. Fish. Sci. 4: 1-432.

Fischer, W. 1959. Huevos, crías y prelarvas de la merluza (Merluccius gayi). Rev. Biol. Mar. 8: 224-249.

GüELFO, A. 2004. http://www.mispeces.com/reportajes/ 2004/abr/merluza/index.asp

Moser, H. G., N. C. H. Lo \& P. E. Sмith. 1997. Vertical distribution of Pacific hake eggs in relation to stage of development and temperature. CalCOFI Rep. 38: 120-126.

Lillo, S., M. Espejo, M. Rojas, V. Ojeda, F. Cerna, R. Céspedes, L. Adasme, H. Miranda, C. Bravo, F. Balbontín, S. Acevedo, M. Braun, V. Valenzuela, H. Miles, J.L. Blanco, J. Letelier \& J. Osses. 1997. Evaluación directa del stock desovante de merluza del sur en la zona sur austral. Informe final proyecto FIP 96-38. 203 p.

Pepin, P., D. C. Orr \& J. T. Anderson. 1997. Time to hatch and larval size in relation to temperature and egg size in Atlantic cod (Gadus morhua). Can. J. Fish. Aquat. Sci. 54 (Suppl. 1): 2-10.

Pool, H., F. Balbontín, C. Montenegro, N. Cortés \& M. Arriaza. 1997. Interacciones tróficas en recursos demersales en la zona sur-austral. Informe final proyecto FIP 94-32. 131 p.

Rubilar, P.S., I. Payá, A. Zuleta, C. A. Moreno, F. Balbontín, H. Reyes, R. Céspedes, H. Pool, L. Adasme \& A. Cuevas. 2002. Dinámica del reclutamiento de merluza del sur. Informe final proyecto FIP 2000-13. 373 p.

Santander, H. \& O. S. de Castillo. 1969. Desarrollo y distribución de huevos y larvas de merluza, Merluccius gayi (Guichenot) en la costa peruana. Bol. Inst. Mar Perú 2: 80-126.

Sernapesca. 2003. Anuario Estadístico de Pesca. Ministerio de Economía, Fomento y Reconstrucción. República de Chile. 140 p. 